\title{
The Necessity of NKCC1: Loss of the Chloride Cotransporter in a Knock-Out Model and Potential Compensatory Mechanisms
}

\author{
Rebecca Wright \\ Department of Pharmacology, University of Oxford, Oxford OX1 3QT, United Kingdom \\ Review of Sipilä et al.
}

During early neuronal development, $\mathrm{GABA}_{\mathrm{A}}$ receptor $\left(\mathrm{GABA}_{\mathrm{A}} \mathrm{R}\right)$ activation typically leads to a depolarizing action, mainly because the activity of the chloride cotransporter, $\mathrm{Na}^{+}-\mathrm{K}^{+}-2 \mathrm{Cl}^{-}$(NKCC1), raises chloride levels within the cell $\left(\left[\mathrm{Cl}^{-}\right]_{\mathrm{i}}\right)$ causing $\mathrm{Cl}^{-}$to move outward through the open channels (Yamada et al., 2004). In contrast, the adult chloride cotransporter KCC2 works to reduce $\left[\mathrm{Cl}^{-}\right]_{\mathrm{i}}$, reversing the chloride driving force to a mature, hyperpolarizing state (Rivera et al., 1999). NKCC1, and its role in promoting excitatory GABAergic activity, is thought to be important in certain developmental events. For example, the expression of NKCC1 within marginal cells of the inner ear has been shown to be vital for the proper development of hearing (Flagella et al., 1999). In the young hippocampus, GABA-mediated depolarization drives activity across groups of neurons, giving rise to correlated network events known as giant depolarizing potentials (GDPs) (Khalilov et al., 1999). In addition, GABA-mediated depolarizations may regulate the maturation of excitatory synapses and dendritic

Received July 28, 2009; revised Sept. 12, 2009; accepted Sept. 22, 2009. This work was funded by the Wellcome Trust. I thank Dr. Colin Akerman and Joseph Raimondo for their helpful comments and support.

Correspondence should be addressed to Rebecca Wright, Department of Pharmacology, University of Oxford, Oxford OX1 3QT, UK. E-mail: rebecca.wright@new.ox.ac.uk.

DOI:10.1523/JNEUROSCI.3637-09.2009

Copyright $\odot 2009$ Society for Neuroscience $\quad$ 0270-6474/09/2913094-03\$15.00/0 morphology (Cancedda et al., 2007; Wang and Kriegstein, 2008), or initiate the developmental upregulation of KCC2 within cells (Ganguly et al., 2001).

Several studies have attempted to investigate the role of GABA-mediated depolarization in early development by prematurely reversing the chloride driving force via overexpression of KCC2. In Xenopus tectal neurons, overexpression of $\mathrm{KCC} 2$ lowers $\left[\mathrm{Cl}^{-}\right]_{\mathrm{i}}$ and disrupts the normal development of excitatory synaptic signaling (Akerman and Cline, 2006). Similarly, reversing the action of GABA in immature cortical neurons has a marked detrimental impact on dendritic morphology (Cancedda et al., 2007).

Recently, a paper published in The Journal of Neuroscience adopted another approach. Rather than imposing a premature, hyperpolarizing $\mathrm{Cl}^{-}$gradient on neurons, Sipilä et al. (2009) used a transgenic mouse model in which the NKCC1 gene $S l c 12 a 2$ had been knocked out, to produce a homozygous NKCC1-null (NKCC1 ${ }^{-/-}$) mutant. Through electrophysiological recordings, they then investigated the role of the cotransporter in maintaining the depolarizing effect of GABA and the impact of this on signaling and developmental mechanisms in the neonatal brain.

First, the authors looked at the impact of NKCC1 loss on GABAergic currents. CA3 pyramidal neurons from $\mathrm{NKCC}^{-1-}$ hippocampal slices were recorded under gramicidin perforated-patch conditions, while local GABA activation was achieved by uncaging GABA compounds with photolysis. Sure enough, at postnatal days 3-4 (P3-P4), the $\mathrm{GABA}_{\mathrm{A}} \mathrm{R}$ reversal potential of $\mathrm{NKCC}^{-/-}$neurons was notably more negative than that of the wild-type (WT) cells of the same age $(\sim 16 \mathrm{mV}$ more negative). In fact the $\mathrm{GABA}_{\mathrm{A}} \mathrm{R}$ reversal potential in mutant cells was comparable to the resting membrane potential, reducing the driving force of the currents to almost nothing. In contrast, the GABAergic driving force of WT cells was still strongly depolarizing.

This near complete loss of GABAergic driving force did not perturb the developmental expression of KCC2. Immunoblots from $\mathrm{NKCCl}^{-/-}$and WT hippocampi revealed no difference in the total levels of KCC2 protein, either at $\mathrm{P} 3 / \mathrm{P} 4$ or $\mathrm{P} 20$, implying that a strong depolarizing GABA signal is not necessary for the developmental upregulation of KCC2 as was proposed by Ganguly et al. (2001).

Next, Sipilä et al. (2009) compared the relative network activity of $\mathrm{NKCC} 1^{-/-}$ and WT slices by patching onto neurons from both genotypes using a low-chloride (4 mM) pipette solution. When clamped at $0 \mathrm{mV}$, WT neurons produced spontaneous bursts of outward current typically associated with GABAergic GDPs. To the authors' surprise, however, similar bursts of GDP-like outward current were also 
found within $\mathrm{NKCC1}^{-/-}$cells, with a mean frequency, amplitude, and duration comparable to those of WT events. Field recordings also showed correlated GDPlike activity across whole groups of cells within $\mathrm{NKCC1}^{-/-}$slices. However, unlike for intracellular events, the average frequency of field GDPs (fGDPs) recorded from $\mathrm{NKCC}^{-/-}$slices was less than half that of WTs, and the duration of such events was also significantly reduced.

GABAergic-dependent GDPs have previously been shown to increase in frequency following $\mathrm{GABA}_{\mathrm{A}} \mathrm{R}$ activation (Khalilov et al., 1999). Consistent with this, application of the selective $\mathrm{GABA}_{\mathrm{A}} \mathrm{R}$ agonist isoguvacine $(5 \mu \mathrm{M})$ caused a significant, transient increase in fGDP frequency in P0-P1 WT slices. However, no such effect was seen in $\mathrm{NKCC}^{-/-}$slices of the same age. Similarly, treatment with the NKCC1 blocker bumetanide $(10 \mu \mathrm{M})$ completely inhibited fGDPs in WT mice, but, as expected, had no detectable effect on the activity of $\mathrm{NKCC} 1^{-/-}$slices. Thus, unlike WT slices, the GDP-like events within the NKCC1 ${ }^{-/-}$slices appeared to be unaffected by manipulations to GABAergic activity.

Given the apparent independence of such GDP-like events in mutant slices to GABAergic signaling, what else could be driving their production? Further investigation into the mechanisms underlying the GDPs revealed notable differences between WT and NKCC1 ${ }^{-/-}$neurons.

While unaffected by manipulations of $\mathrm{GABA}_{\mathrm{A}} \mathrm{R}$ activity, GDPs in $\mathrm{NKCC1}^{-/-}$ slices were susceptible to AMPA receptor (AMPAR) blockers. Both NBQX (10-15 $\mu \mathrm{M})$ and GYK153655 (20 $\mu \mathrm{M})$ successfully blocked network events in both WT and $\mathrm{NKCC}^{-/-}$slices. These results are interesting for a number of reasons: first, they indicate that functional AMPARs are present in $\mathrm{P} 0-\mathrm{P} 1$ mouse hippocampal cells, and that they can play a role in the generation of GDPs. Second, the fact that AMPARs appear normal in knock-out animals, suggests that, contrary to previous work in cortex (Wang and Kriegstein, 2008), early depolarizing GABA may not be essential for the maturation of excitatory synapses in the hippocampus. Third, the complete blockade of network activity across $\mathrm{NKCC1}^{-/-}$pyramidal cells with AMPAR antagonists implies that these receptors play a crucial role in the generation of fGDPs in the absence of a depolarizing GABA signal.

As a final analysis, spontaneous activity across WT and $\mathrm{NKCCl}^{-/-}$neurons was compared by blocking all ionotropic glutamatergic and GABAergic signaling. Under these conditions the intrinsic spiking frequency of P6-P7 $\mathrm{NKCC1}^{-/-}$cells was six times higher than the equivalent firing rate of WT neurons. From this, the authors concluded that loss of early depolarizing GABAergic actions led to a compensatory enhancement of intrinsic neuronal excitability within the $\mathrm{NKCC1}^{-1-}$ cells, and that this increased excitability, along with recruitment of functional AMPARs, enabled the generation of GDP-like events within the hippocampal network. Whether changes to the intrinsic properties of the $\mathrm{NKCC}^{-/-}$cells could be considered truly homeostatic is perhaps unclear, since the resultant fGDPs were still notably different than those of WT slices in size and frequency.

One of the most compelling pieces of evidence in support of this hypothesis was the observation of a similar compensatory upregulation in WT neurons following pharmacological blockade of NKCC1 activity. While initially blocking GDPs, prolonged application of bumetanide over the course of 2-3 h, led to an increase in spontaneous cellular spiking, as measured by the frequency of $\mathrm{Ca}^{2+}$ transients. This upregulation of neuronal activity coincided with a reinstatement of networkwide fGDP events. Such spontaneous spiking activity could be the result of a number of intrinsic conductances within CA3 neurons. As the authors acknowledge, the next step would be to dissect these various channels to determine the precise mechanisms that lead to this increase in intrinsic firing.

As an interesting comparison, another study, also published in The Journal of Neuroscience, recently investigated the role of NKCC1 in a similar knock-out model (Pfeffer et al., 2009). The findings however, deviate from those of Sipilä et al. (2009) on several key points. NKCC1 ${ }^{-1-}$ pyramidal neurons in Pfeffer et al.'s (2009) recordings still exhibited a depolarizing, be it much attenuated, GABAergic current. Furthermore, the authors found that loss of NKCC1 did impede the generation of GDP-like activity, significantly reducing the frequency of intracellular events as well as both the frequency and duration of extracellular fGDPs. Maturation of excitatory synapses was also found to be delayed in their $\mathrm{NKCCl}^{-1-} \mathrm{mu}$ tants. However, unlike previous work in cortical neurons (Cancedda et al., 2007), the reduction in GABAergic depolarizing driving force did not impede the morpho- logical maturation of dendrites within the hippocampal cells.

How can two knockdown studies targeting the same gene result in such distinctive phenotypes? The differences may be due to environmental factors, or they may stem from variations in the underlying genetic backgrounds. Sipilä et al. (2009) point out that their strain of mouse is different to the one used by Pfeffer et al. (2009). This distinction opens the possibility of indirect effects occurring through "modifier" genes, allelic variations in genes other than the target knock-out gene that can alter the final phenotype (Sigmund, 2000). Identifying such modifier genes, and understanding their influence upon the role of one's gene of interest, should be an important consideration during the development of mutant models and the consequential interpretation of data.

Nevertheless, the data of Sipilä et al. (2009) illustrate that compensatory mechanisms can enable the developing brain to cope relatively well in the absence of depolarizing GABA. While there is consensus that the NKCC1 cotransporter plays a critical role in the development of hearing (Flagella et al., 1999; Pace et al., 2000), work by groups such as Sipilä et al. (2009) and Pfeffer et al. (2009) shows that NKCC1 is not always essential for the development of other features, such as the maturation of excitatory synapses, or the proper morphology of dendrites. It may be that only when perinatal GABAergic signals are driven to be prematurely hyperpolarizing, via the overexpression of $\mathrm{KCC} 2$ (Akerman and Cline, 2006; Cancedda et al., 2007), that detrimental changes to the growth and activity of the young brain are more consistently seen.

\section{References}

Akerman CJ, Cline HT (2006) Depolarizing GABAergic conductances regulate the balance of excitation to inhibition in the developing retinotectal circuit in vivo. J Neurosci 26: 5117-5130.

Cancedda L, Fiumelli H, Chen K, Poo MM (2007) Excitatory GABA action is essential for morphological maturation of cortical neurons in vivo. J Neurosci 27:5224-5235.

Flagella M, Clarke LL, Miller ML, Erway LC, Giannella RA, Andringa A, Gawenis LR, Kramer J, Duffy JJ, Doetschman T, Lorenz JN, Yamoah EN, Cardell EL, Shull GE (1999) Mice lacking the basolateral Na-K-2Cl co-transporter have impaired epithelial chloride secretion and are profoundly deaf. J Biol Chem 274:26946-26955.

Ganguly K, Schinder AF, Wong ST, Poo M 
(2001) GABA itself promotes the developmental switch of neuronal GABAergic responses from excitation to inhibition. Cell 105:521-532.

Khalilov I, Dzhala V, Ben-Ari Y, Khazipov R (1999) Dual role of GABA in the neonatal rat hippocampus. Dev Neurosci 21:310-319.

Pace AJ, Lee E, Athirakul K, Coffman TM, O’Brien DA, Koller BH (2000) Failure of spermatogenesis in mouse lines deficient in the Na-K-2Cl cotransporter. J Clin Invest 105:441-450.

Pfeffer CK, Stein V, Keating DJ, Maier H, Rinke I, Rudhard Y, Hentschke M, Rune GM, Jentsch TJ, Hübner CA (2009) NKCC1- dependent GABAergic excitation drives synaptic network maturation during early hippocampal development. J Neurosci 29: 3419-3430.

Rivera C, Voipio J, Payne JA, Ruusuvuori E, Lahtinen H, Lamsa K, Saarma M, Kaila K (1999) The $\mathrm{K}-\mathrm{Cl}$ cotransporter KCC2 renders GABA hyperpolarizing during neuronal maturation. Nature 397:251-255.

Sigmund CD (2000) Are studies in genetically altered mice out of control? Arterioscler Thromb Vasc Biol 20:1425-1429.

Sipilä ST, Huttu K, Yamada J, Afzalov R, Voipio J,
Blaesse P, Kaila K (2009) Compensatory enhancement of intrinsic spiking upon NKCC1 disruption in neonatal hippocampus. J Neurosci 29:6982-6988.

Wang DD, Kriegstein AR (2008) GABA regulates excitatory synapse formation in the neocortex via NMDA receptor activation. J Neurosci 28: 5547-5558.

Yamada J, Okabe A, Toyoda H, Kilb W, Luhmann HJ, Fukuda A (2004) $\mathrm{Cl}^{-}$uptake promoting depolarizing GABA actions in immature rat neocortical neurones is mediated by NKCC1. J Physiol 557:829-841. 